\title{
ACCOUNTING TRANSACTIONS OF CONCORDATUM IN TERMS OF TURKISH ACCOUNTING REGULATIONS
}

\author{
DOI: 10.17261/Pressacademia.2020.1244
}

PAP- V.11-2020(16)-p.79-83

Ugur Kaya ${ }^{1}$, Yasar Bayraktar ${ }^{2}$, Oguz Yusuf Atasel ${ }^{3}$

${ }^{1}$ Karadeniz Technical University, Department of Business, Trabzon, Turkey ukaya105@yahoo.com, ORCID: 0000-0003-1358-7122

${ }^{2}$ Karadeniz Technical University, Department of Business, Trabzon, Turkey ysr bayraktar@hotmail.com, ORCID: 0000-0002-6974-5292

${ }^{3}$ Karadeniz Technical University, Department of Business, Trabzon, Turkey oguzatasel@ hotmail.com, ORCID: 0000-0003-1654-9850

To cite this document

Kaya, U., Bayraktar, Y. ve Atasel, O. Y., (2020). Accounting transactions of concordatum in terms of Turkish accounting regulations. PressAcademia Procedia (PAP), V.11, p.79-83

Permanent link to this document: http://doi.org/10.17261/Pressacademia.2020.1244

Copyright: Published by PressAcademia and limited licensed re-use rights only.

\begin{abstract}
Purpose- The purpose of this study is to explain the accounting principles for the issues that are special in corcondatum transactions in the framework of Tax Procedure Law, General Communique on Accounting System Application, Turkish Accounting and Financial Reporting Standards and the Financial Reporting Standard for Large and Medium-Sized Businesses.

Methodology- Accounting of concordatum transactions in terms of creditor and debtor will be handled within the framework of existing accounting regulations. Thus, similarities and differences in the accounting of these transactions will be revealed.

Findings- While the receivable given up by concordatum is written as expense for the creditor as of the relevant period; the amount, which is a profit in terms of the debtor, is monitored in a special provision account. The amount that is tracked in the provision account and deducted for loss within three years and not fully redeemable is transferred to the relevant operating accounts. However, it has been determined that there are different applications in the literature. In addition, it was determined that there are differences in terms of doubtful receivables arising from temporary and final deadline in the concordatum process.

Conclusion- Consideration of all existing regulations in the accounting of the concordatum in Turkey and comparative disclosures by the creditor and debtor has an important place in terms of compliance on relevance and faithful representation in financial statements.
\end{abstract}

Keywords: Concordatum, Tax Procedural Law, TMS/TFRS, BOBI FRS.

JEL Codes: M41, M48, M49

\section{TÜRKIYE'DEKi MUHASEBE DÜZENLEMELERI AÇISINDAN KONKORDATO IŞLEMLERININ MUHASEBELEŞTiRILMESI}

\section{ÖZET}

Amaç- Bu çalışmanın amacı, konkordato işlemlerinde özellik arzeden hususların Vergi Usul Kanunu, Muhasebe Sistemi Uygulama Genel Tebliği, Türkiye Muhasebe ve Finansal Raporlama Standartları ve Büyük ve Orta Boy İşletmeler için Finansal Raporlama Standardı çerçevesinde muhasebeleştirilme esaslarını açıklamaktır.

Yöntem- Alacaklı ve borçlu taraflar açısından konkordato işlemlerinin muhasebeleştirilmesi hususu mevcut muhasebe düzenlemeleri çerçevesinde ele alınacaktır. Böylece konkordato işlemlerinin muhasebeleştirilmesindeki benzerlik ve farklııklar ortaya konacaktır.

Bulgular- Konkordato yoluyla vazgeçilen alacak, alacaklı işletme için ilgili dönem itibariyle gider yazılırken; borçlu işletme açısından kar niteliğinde olan tutar, özel bir karşılık hesabında izlenmektedir. Karşılık hesabında izlenip üç yıl içerisinde zarara karşıllk mahsup edilen ve tamamı itfa edilemeyen tutar, ilgili sonuç hesabına aktarımaktadır. Ancak literatürde farklı uygulamaların olduğu tespit edilmiştir. Ayrıca şüpheli ticari alacaklar açısından konkordato sürecinde geçici mühlet ve kesin mühletten kaynaklanan farklılıkların olduğu be lirlenmiştir. Sonuç- Konkordato işlemlerinin muhasebeleştirilmesinde Türkiye'deki mevcut düzenlemelerin dikkate alınması ve karşılaştırmalı olarak açıklanması, paydaşlar nezdinde ilişki tarafların sundukları bilgilerin ihtiyaca ve gerçeğe uygunluğu açısından önemli bir yere sahiptir.

Anahtar Kelimeler: Konkordato, Vergi Usul Kanunu, TMS/TFRS, BOBi FRS.

JEL Kodlar: M41, M48, M49 


\section{Gíriş}

Türkiye' de faiz oranları, döviz kurları, cari açık, enflasyon gibi bir takım makroekonomik göstergelerde yaşanan değişimlerin beraberinde getirdiği belirsizlik ortamı; işletmeler açısından mali istikrarsızlıkların oluşmasına, borçlanma maliyetlerinin artma sına, borç ödeme gücünün azalmasına ve bu nedenle birçok işletmenin iflas etmesine ya da iflasın eşiğine gelmesine neden olmaktadır. Bu doğrultuda işletmelerin sürdürülebilirliğini ve ekonomik refahı sağlayabilmek için İcra İflas Kanunu’nda yer alan konkor dato müessesesinin işlevi artırılarak; borçlu işletmelerin borçlarını alacaklıların rızası doğrultusunda yargının nihai kararına göre yapılandırabilmelerinin yolu açılmıştır.

Konkordato müessesesi, mali yapısı güçsüzleşen, likidite sorunları yaşayan borçlu işletmeler ve ilişkili alacaklı taraflar açısından önem arz etmektedir. Zira bu hukuki yol sayesinde borçlu işletmelerin borcunu ödeyebileceği şartlar için zemin hazırlanırken; alacaklılar için de iflas tasfiyesine kıyasla daha fazla tutarda alacaklarını tahsil etme imkânı sağlanmaktadır. Böylece borcunu ödemekten acze düşen ya da vadesinde ödeyemeyen borçlunun borçları yapılandırılarak ticari faaliyetleri sürdürülebilir kılınmaktadır. Ayrıca her iki taraf için hukuki bağlayıcılığı olan konkordato projesi sayesinde karşılıklı çıkarların dengesi de gözetilebilmektedir. Türkiye' nin içinde bulunduğu durum nedeniyle önemli bir gündem olan konkordato işlemlerinin muhasebe uygulamaları da önem arz etmektedir. Nitekim bu çalışmada kavramsal olarak konkordatoya ve söz konusu hukuki sürecin işleyişine yer verildikten sonra, ilişkili taraflar açısından borçların, vazgeçilen alacakların ve tahsili şüpheli hale gelen alacakların muhasebeleştirilmesine dair özellikli hususlar, Vergi Usul Kanunu (VUK), Muhasebe Sistemi Uygulama Genel Tebliği (MSUGT), Türkiye Muhasebe ve Finansal Raporlama Standartları (TMS/TFRS) ile Büyük ve Orta Boy İ̧̧letmeler için Finansal Raporlama Standardı (BOBi FRS) çerçevesinde açıklanacaktır.

\section{KAVRAMSAL ÇERÇEVE}

Konkordato, dürüst ve iyi niyetli bir borçlunun, alacaklı çoğunluğunun (2/3) rızası üzerine verilen mahkeme kararı doğrultusunda borçlarını kısmen ve/veya vadelerle ödemesini öngören cebri icra hukukuna özgü bir müessesedir (Konca, 2018, s.7).

İcra ve İflas Kanunu'nda borçlunun borçlarını tasfiye edebilmesini ve ticari faaliyetlerini sürdürülebilir kılmasını sağlamaya yönelik olarak iyileştirme projesi bağlamında düzenlenen konkordato, 15.03.2018 tarihli 30361 sayılı Resmi Gazete'de yayımlanan 7101 sayılı İcra ve íflas Kanunu ve Bazı Kanunlarda Değişiklik Yapılması Hakkında Kanun ile işlevselleştirilerek; borçluların lehine olan ancak alacaklılara söz hakkı tanımayan bir diğer iyileştirme projesi mahiyetindeki iflas ertelemesi müessesinin yerine yürürlüğe girmiştir (Bilen ve Güler, 2019, s. 81). Borca batık olan sermaye şirketleri ya da kooperatiflerin, mali yapılarının iyileştirilmesine yönelik olan iflas ertelemesinde yasal süreç, yalnızca borçlu ve yargı birimi arasında işletildiğinden, ilişkili tarafların hak ve menfaatleri eşit düzeyde korunmamaktadır (Konca, 2018, s.9). Ayrıca bu müessese, iflas yargılamasında borçluyu geçici hukuki koruma altına aldığından borçlu lehine verilecek iflas ertelemesi kararı, mevcut iưa takibi işlemlerini de geçici olarak askıya almaktadır (Arzova, Yavaş ve Küçük, 2016, s.47). Bununla birlikte iflas ertelemede yargılamanın uzun sürmesi ve buna bağlı olarak alınan tedbir kararlarının bağlayıcılığının da uzun olması alacaklıların alacaklarını zamanında tahsil edememesine ve böylece mali sıkıntılar yaşayarak iflas eşiğine gelmesine neden olabilmektedir (Konca, 2018, s.10; Uyar, 2019, s.10). Bu nedenle ilişkili taraflar arasındaki adaletin tesis edilmesi ve ekonomik refah ortamının oluşturulması için konkordato müessesi işler kılınmıştır. Böylece borçluya borcunu, alacaklıların rıza gösterdiği ölçüde ödeyebilme imkânı sağlanarak; hem alacaklı hem de borçluların haklarının gözetilebileceği bir zemin hazırlanmıştır.

İcra İflas Kanunu'nda konkordato, adi (iflas dışı), iflas içi (iflastan sonra) ve mal varlığının terki suretiyle konkordato olarak düzenlenmiştir (Börü, 2019, s. 174). Öte yandan literatürde konkordatonun; yapılış amacına göre mal varlığının terki ya da borçların tasfiyesi (adi konkordato) yoluyla; zamanına göre iflas içi ve iflas dışı; biçimine göre indirim (tenzilat), vade ya da karma (indirim-vade) olarak sınıflandırıldığı görülmektedir (Konca, 2018, s.10; Bayazıtlı vd., 2019, s.46). Konkordato türlerinden uygulamada sıklıkla karşılaşılanı, borçlunun borcunu ödemek üzere alacaklılara teklifte bulunduğu borçların tasfiyesi mahiyetindeki adi konkordatodur (Börü, 2019, s.174). Bu çalışma kapsamında borçların tasfiyesi (adi) yoluyla konkordato ve işleyişi ele alınacaktır.

Konkordato süreci, borçlu ya da iflasa tabi borçlusu için alacaklı tarafından öncelikle gerekli evrakların hazırlanıp ilgili gider avansının yatırımasıyla birlikte asliye ticaret mahkemesine yapılacak başvuruyla başlamaktadır (Özdemir, 2018, s.3). Bu bağlamda ön projenin hazırlanması ve borçlunun mali durumuna işaret eden bir takım bilgi ve belgelerin ilgili yargı birimine sunulması gerekmekted ir (Temiz, 2019, s.271). Konkordato talebinin ardından yetkili yargı birimince sunulan evrakların şekli olarak incelemesi yapılarak konkordato talebi değerlendirilmektedir. Yargı birimine sunulan belgelerin tam olması durumunda borçlunun mal varlığının korunmasına yönelik tedbir alınmak suretiyle üç aylık geçici mühlet kararı verilmektedir. Bu süre, geçici suretle gör evlendirilen konkordato komiseri ya da borçlunun talebi üzerine iki ay daha uzatılabilmektedir (Konca, 2018, s.13-14). Bu süreler içerisinde alacaklılar açısından itiraz yolu kapalıdır. Geçici mühlet süresinde yargı merciinde, konkordato projesinin başarılı olabileceğine dair kanaat uyandırması halinde bir yıllık kesin mühlet verilmektedir. Bu süre içerisinde alacaklılar kurulu oluşturularak alacakların akıbeti değerlendirilmekte olup, ayrıca kesin mühlet süresi, ilgililerin talebi üzerine altı ay daha uzatılabilmektedir. (Bilen ve Güler, 2019, s.86). Alacaklılar kurulundaki alacakların ve alacaklıların yarısı ya da alacakların ü çte ikisi ve alacaklıların dörtte birini geçen bir çoğunluk tarafından onaylandığı takdirde konkordato projesi kabul edilmiş sayılmaktadır (Yavuz, 2019, s.216). Kabul edilen proje, konkordato komiseri tarafından hazırlanan gerekçeli rapor ve ilgili dosyanın görevli mahkemeye sunulmaktadır. Böylece tasdik yargılamasına geçilmektedir. Yargı merciinde alacaklıların rızasıyla tayin edilen ödeme miktarı ve zamanı içeren konkordato projesinin başarıyla sonuçlanabileceğine dair kesin kanaat oluşması halinde hem alacaklı hem de borçlu açısından bağlayıcı nitelikteki içeren tasdik kararı verilmektedir (Temiz, 2019, s.272). Aksi halde konkordato talebi reddilerek borçlunun iflâsa tabi olması ve iflâsın gerçekleşme sebeplerinin mevcut olmasına bağlı olarak borçlunun iflâsına res'en karar verilmektedir (Buyrukoğlu, 2019, s.264).

\section{LITERATÜR}

Konkordato müessesesinin süreci, işleyişi ve taraflar açısından hukuki boyutlarına ve konkordato projesinin tasdiki ya da red dedilmesi durumuna göre mali nitelikli işlemlerin nasıl muhasebeleştirilmesi gerektiğine dair literatürde bir takım araştırmalar mevcuttur. Bu kapsamda Aslanoğlu, Özalp ve Özalp (2018), konkordato başvurusu ve geçici mühletine, Bilen ve Güler (2019), vergi hukuku açısından ala caklıların 
akıbetine, Buyrukluoğlu (2019), konkordato sürecinde kamusal alacakların vaziyetine, Göç, Alpaslan ve Güneş (2019), konkordato komiserinin geçici ve kesin mühlet içerisindeki görev ve sorumluluklarına, Börü (2019), alacaklıların alacaklarını bildirme sürelerine ve zamanında bildirilmeyen alacaklara ilişkin hükümlere, Yavuz (2019), alacaklıların konkorda to mühletleri içerisindeki itiraz ve dava haklarına, Özdemir (2019), konkordato sürecinde adli muhasebenin ön proje, bilgi ve gerekli belgelerin hazırlanması, alacaklılara sunulacak tekl ifin görüşülmesi gibi konularda destekleyici bir rol üstlendiğine, Koç ve Uzay (2020) ise konkordatoya başvurma nedenlerinden hareketle işletme sürekliliği açısından risk ve kontrol hususlarına açıklık getirmektedir.

Öte yandan Apalı (2018), Özdemir (2018), Coşkun (2019) ve Temiz (2019) Vergi Usul Kanunu uyarınca vazgeçilen alacaklar kapsamında konkordato işlemlerinin muhasebeleştirilmesi hususunu ele alarak borçlu ve alacaklılar açısından Muhasebe Sistemi Uygulama Genel Tebliği' ne göre mali nitelikli işlemlerin muhasebeleştirilmesine yönelik örnekler vermiştir. Serçemeli ve Okutan (2019) ise konkordato projesi kapsamında sunulması gereken finansal tabloların hazırlanmasına yönelik Tekdüzen Muhasebe Sistemi'ne göre örnek vaka oluşturm uş ve bir işletmenin mevcut mali tablolarını hem rayiç bedel hem de iflas değerine göre karşılaştırmalı olarak sunmuştur. Görüldüğü üzere, literatürde konkordato işlemlerinin muhasebeleştirilmesine yönelik yapılan araştırmalar yalnızca Vergi Usul Kanunu (VUK) uyarınca Muhasebe Sistemi Uygulama Genel Tebliği (MSUGT)'ne göre gerçekleştirilmiştir.

Konkordato sürecine dair yapılan açıklamalar ışı̆ı̆ında ele alınan bu çalışma da söz konusu işlemlerin muhasebeleştirilmesinde ala caklı ve borçlu açısından özellikli hususlar; VUK, MSUGT, TMS/TFRS ve BOBi FRS açııından açıklanacaktır. Böylece tasdik edilmiş konkordato projesi ile ilgili olarak bilgi kullanıcılarına sunulacak mali tablolar ihtiyaca ve gerçeğe uygun bir biçimde hazırlanabilecektir. Çalışmanın bu yönüyle literatüre katkı sağlaması beklenmektedir.

\section{MUHASEBE UYGULAMALARI}

Vergi Usul Kanunu'nun 324. maddesi uyarınca vazgeçilen alacak kapsamında düzenlenen konkordato ya da sulh yoluyla vazgeçilen alacaklar, mahkeme kararı ya da kanıtlayııı bir belgeye göre tahsiline imkân kalmayan nitelikteki değersiz alacaklardan farklıdır. Zira konkordato ve sulh yoluyla alacaktan vazgeçmede alacaklıların rızası gözetilmektedir. Konkordato, borçlunun borcunun bir kısmından kurtulmasına ya da ödeme koşullarının değiştirilmesiyle birlikte yaşanılan likidite dar boğazından kurtulmasına ve işletmesini sürdürülebilir kıımasına imkân sağlamaktadır. Ayrıca bu hukuki müessese sayesinde alacaklı da borçlunun iflas etmesi halinde elde edemeyeceği alacağının bir kısmını tahsil edebilme imkânına kavuşmaktadır

Konkordato yoluyla vazgeçilen alacak, alacakı işletme için zarar, borçlu için kar niteliğindedir. Bu bağlamda alacaklı açısından zarar, ilgili dönem itibariyle "689 Diğer Olağandışı Gider ve Zararlar Hesabı"na kaydedilmektedir. Borçlu işletme açısından ise kar niteliğinde olan bağışlanan borç karşıllğıyla ilgili tutar, "549 Özel Fonlar Hesabı" gibi özel bir karşıllk hesabında izlenmektedir. Karşılık hesabında izlenen tutar, borcun bağışlandığı yılın sonundan itibaren izleyen dönemlerde oluşacak zarara karşılık mahsup edilmek üzere üç yıl süreyle bekletilmektedir. Üç yıllık süre zarfında zarara karşılık mahsup edilmeyen karşılık tutarı "671 Önceki Dönem Gelir ve Karlar Hesabı” gibi bir gelir hesabına aktarılmaktadır. Öte yandan iş terki, ölüm, birleşme ve devir gibi durumların olması halinde ise söz konusu fon tutarı, üç yıl bekletilmeksizin ilgili yılda sonuç hesaplarına devredilmektedir. Literatür incelendiğinde Apalı (2018: 218), Özdemir (2018: 9) ve Temiz (2019: 275) tarafından “591 Dönem Net Zararı Hesabı” yerine “690 Dönem Kar veya Zararı Hesabı”nın kullanıldığı görülmektedir.

Tahakkuk esasına dayalı olarak ticari ya da zirai kazancın sonucunda gelir kaydedilen alacağın, konkordato kapsamında vazgeçilen kısmı gider olarak yazılmaktadır. Bu bağlamda işletme hesabı esasına göre defter tutan işletmeler diğer bir ifadeyle II. sınıf tacirler ise değersiz hale gelen alacaklarııı doğrudan gider hesabına aktarabilmektedir (Sürmen, 2020, s.129).

Konkordato projesinin tasdik edilmesiyle birlikte alacaklı kendi rızası doğrultusunda alacağının bir kısmından vazgeçmektedir. Bununla bir likte alacağın vadesinde de bir takım değişiklikler meydana gelebilmektedir. Bu kapsamda alacak ve borç ile ilgili olarak dönemsellik kavramı gereği her iki taraf açısından kayıt düzenin sağlanması gerekmektedir. Öte yandan alacaklılar açısından konkordato sürecinde geçici mühlet öncesi, dava ya da icra safhasında bulunan şüpheli hale gelmiş alacaklara yönelik ayrılan karşılık ile ilgili herhangi bir düzeltmenin yapılmasına gerek yoktur. Bunun yanı sıra dava ya da icra safhasına intikal etmemiş alacaklar için geçici mühlet ilanının gerçekleştiği dönem itibariyle karşılk ayrılabilmektedir. Bu bağlamda “654 Karşıllık Giderleri Hesabı”nın borcuna karşılık "129 Şüpheli Ticari Alacaklar Hesabı” alacaklandırımaktadır. Ayrılacak karşılık tutarı, söz konusu alacakla ilgili olarak mevcut teminatı aşan kısma yöneliktir (TÜRMOB, 2019). Öte yandan teminatsız kısım için ayrılan karşılık tutarı, geçici mühletin kaldırııp konkordatonun reddedilmesi halinde ilgili hesap döneminde iptal edilerek "644 Konusu Kalmayan Karşııklar Hesabı" gibi bir gelir hesabına aktarılmaktadır (TÜRMOB, 2019). Bununla birlikte vadesi gelmemiş alacaklar, geçici ya da kesin mühlet süresi içinde muaccel hale geldiğinde şüpheli alacak olarak değerlendirilebilmektedir. Ancak geçici mühletin verildiği hesap dönemi itibariyle karşılık ayrılmayan alacağa sonraki hesap döneminde kesin mühlet kararının verilmesi halinde şüpheli alacak karşılı̆̆ı ayrılamamaktadır. Öte yandan konkordato projesinin tasdik edilmesine bağlı olarak va zgeçilen alacak niteliğindek $i$ tutar zarar olarak muhasebeleștirilirken ilgili karşııı tutarı iptal edilmektedir. Ayrıca proje kapsamında vazgeçilmeyen ala cağın vadesi/tutar değişeceğinden bu alacaklar için ayrılan karşılıkların da ilgili dönem itibariyle düzeltilmesi gerekmektedir (TÜRMOB, 2019).

Öte yandan işletmenin ticari ve ticari olmayan faaliyetleri sonucunda meydana gelen senetli ve senetsiz alacakları ile borçlarının, ilk kayda alındı̆̆ı tarih ve tahsil edileceği tarih arasındaki vade süresinin bir yıl ve altında olması halinde alacak ve borçlar itibari değer üzerinden ölçülmektedir. Bu durumun aksine vade süresinin bir yıldan uzun olması halinde ise ilgili alacak ve borçlar itfa edilmiş değer üzerinden muhasebeleştirilmektedir (BOBi FRS, prf.9.8). TFRS 9 uyarınca ticari alacakların önemli bir finansman bileşenine sahip olmaması (ya da işletmenin ilgili Standardın 63. paragrafina göre kolaylaștıııı uygulamayı seçmesi) durumunda, bu alacaklar ilk defa finansal tablolara alınması sırasında işlem bedeli (gerçeğe uygun değer) üzerinden ölçülmektedir (TFRS 9, prf.5.1.1.). Sonraki ölçümlerde ise itfa edilmiş maliyet geçerli olup, kolaylaştıııı uygulamalar göz önünde bulundurularak ticari alacak ve borçlar kayıt altına alınmaktadır (TFRS 9, prf.5.2.1.).

BOBi FRS uyarınca itfa edilmiş değer üzerinden ölçülen ticari alacak ve borçların etkin faiz yöntemine göre hesaplanan faiz tutarı, Kar veya Zarar Tablosu'nda Esas Faaliyetlerden Diğer Gelirler ya da Esas Faaliyetlerden Diğer Giderler kalemlerinde izlenmektedir. Bununla birlikte 
ticari alacaklara ilişkin değer düşüklüğü zararı, gözlemlenebilir kanıtların varlığına bağlı olarak dikkate alınıp karşılık ayrılmaktadır. Gözlemlenebilir kanıtlar ise borç verenin, borçlunun ekonomik ya da yasal sebeplerle yaşadığı mali sıkıntılardan ötürü borçluya normal şartlarda sağlamayacağı bir imtiyaz sağlaması, borçlunun iflas etmesinin ya da diğer bir finansal yapılandırma durumunun muhtemel hale gelmesi gibi durumlara dayandırılmaktadır. Bu bağlamda ticari alacaklarda meydana gelen değer düşüklüğü zararı Esas Faaliyetlerden Diğer Giderler üzerinden kaydedilmektedir (BOBi FRS, prf.9.33-34). Öte yandan TFRS'de ise beklenen kredi yaklaşımı çerçevesinde değer düşüklüğü zararı hesaplanıp muhasebeleştirilmektedir. Bu açıklamalar ışığında TFRS ve BOBi FRS uyarınca KGK tarafından yayınlanan "Finansa Raporlama Standartlarına Uygun Hesap Planı Taslağı" çerçevesinde değer düşüklüğü karşılıklarının "651 Esas Faaliyet Alacaklarına İlişkin Değer Düşüklüğü Karşıık Giderleri Hesabı”nın borcuna karşılık “129 Ticari Alacaklar Değer Düşüklüğü Karşılıkları Hesabı (-)”nın alacağına kaydedilmektedir. Öte yandan karşılık ayrılmış olan alacağın tahsili ya da tahmin değişikliğine bağlı olarak ayrılan değer düşüklüğü zararının kısmen ya da tamamen iptal edilmesi halinde ilgili tutar "129 Ticari Alacaklar Değer Düşüklüğü Karşılıkları Hesabı (-)"nın borcunda izlenmektedir. Ayrıca değer düşüklüğü karşılığının iptalinde tahsil ya da tahmin değişikliğinin karşılığın ayrıldığı cari dönem itibariyle gerçekleşmesi halinde “651 Esas Faaliyet Alacaklarına İlişkin Değer Düşüklüğü Karşılık Giderleri Hesabı” alacaklandırılmaktadır. Bunun yanı sıra değer düşüklüğü zararının iptalinin sonraki dönemlerde meydana gelmesi durumunda ilgili tutar "641 Esas Faaliyet Alacaklarına Illişkin Konusu Kalmayan Karşılıklar Hesabı”nın alacağında izlenmektedir. Öte yandan alacağın tahsilinin imkânsız olması halinde "129 Ticari Alacaklar Değer Düşüklüğü Karşııkları Hesabı (-)” borçlandırıırken, “127 Şüpheli Ticari Alacaklar Hesabı” alacaklandırılmaktadır. Bununla birlikte gerçekleşen zararın ayrılan karşılık tutarından fazla olması halinde aşan tutar "654 Esas Faaliyetlerden Diğer Çeşitli Gider ve Zararlar Hesabı"nın borcuna kaydedilmektedir.

\section{SONUÇ VEÖNERILER}

Konkordato, işletmelerin karşılaştıkları likidite sıkıntılarının meydana getirdiği darboğazın aşılmasında etkili bir hukuki müessese olup, borçlu ve alacaklıların üzerinde anlaşmaya vardığı ortak bir ödeme projesidir. Yasal olarak bağlayıcılığı olan bu proje sayesinde borçlu, alacakıların rızası doğrultusunda ödeyebileceği borç tutarını ve vadeyi tayin ederek borcunu yapılandırabilmektedir. Ayrıca konkordato projesi sonucunda alacaklı da alacaklarını kısmen de olsa tahsil edebilme imkânı elde etmektedir.

Konkordato projesinin tasdik edilmesiyle birlikte borçlu ve alacaklıların, yapılandırılan borç ve alacaklarının nihai durumunu yansıtacak şekilde muhasebeleştirme esaslarını dikkate almaları gerekmektedir. Dolayısıyla konkordato işlemlerinin muhasebeleştirilmesinde Türkiye'deki mevcut düzenlemelerin dikkate alınması ve karşılaştırmalı olarak açıklanmasının, paydaşlar nezdinde ilişki tarafların sundukları bilgilerin ihtiyaca ve gerçeğe uygunluğu açısından önemli bir yere sahip olduğu ifade edilebilir. Bu bağlamda ilgili yargı birimince verilen geçici ve kesin mühlet süreleri içerisinde alacaklılar açısından şüpheli hale gelen alacakların ve projenin tasdik edilmesiyle birlikte vazgeçilen alacakların; borçlular açısından ise bağışlanan ve vadesi değiştirilen borçların usulüne uygun olarak kaydedilmesi ve raporlanması gerekmektedir. Zira mevcut ve potansiyel yatırımcılar açısından etkili yatırım kararlarının alınmasında usulüne ve gerçeğe uygun olarak hazırlanıp sunulan mali tabloların yadsınamayacak derece önemli olduğu belirtilebilir.

\section{KAYNAKÇA}

Apalı, İ. (2018). Vergi usul kanunu açısından konkordato ilanı kapsamında vazgeçilen alacakların değerlendirilmesi ve muhasebeleştirilmesi. Mali Çözüm, 28 (150), 211-219.

Arzova, S. B., Yavaş, M. ve Küçük, B. (2016). Hukuki ve mali yönden iflasın ertelenmesi ve borca batıklık bilançosu (3. Baskı). Ankara: Seçkin Yayıncilık.

Aslanoğlu, S., Özalp, A.D. ve Özalp, A. R. (2017). Bir yeniden yapılandırma kurumu olarak konkordato başvurusu, geçici mühlet ve gerekçeleri Ekonomi İşletme Siyaset ve Uluslararası İlişkiler Dergisi, 3 (2), 63-78.

Bayazıtlı, E. vd. (2019). Konkordato komiserliği temel eğitim kitabı. T.C. Adalet Bakanlığı, Bilirkişilik Daire Başkanlığı Ya yını. Ankara.

Bilen, C. İ. ve Güler, S. (2019). Konkordato ve alacakların akıbeti. Vergi Dünyası, 38 (449), 81-97.

Kamu Gözetimi Kurumu (2018). Büyük ve Orta Boy İşletmeler İçin Finansal Raporlama Standardı (BOBi FRS). Erişim adresi https://www.kgk.gov.tr/Portalv2Uploads/files/PDF\%20linkleri/bobi_frs.PDF

Kamu Gözetimi Kurumu (2019). Türkiye Finansal Raporlama Standardı (TFRS). Erişim adresi https://www.kgk.gov.tr/Portalv2Uploads/files/Duyurular/v2/TFRS/TFRS_2020/TFRS\%209.pdf

Börü, L. (2019). Adi konkordatoda alacaklıların alacaklarını bildirmesi. İnönü Üniversitesi Hukuk Fakültesi Dergisi, 10 (1), $173-186$.

Buyrukoğlu, S. (2019). 7101 sayılı kanun çerçevesinde konkordato ve kamusal alacakların durumu. Fiscaoeconomia, 3 (1), $259-267$.

Coşkun, D. (2019). Konkordato sürecinin muhasebe uygulamalarına etkisinin incelenmesi. Yayımlanmamış yüksek lisans tezi. Marmara Üniversitesi-Sosyal Bilimler Enstitüsü.

Göç, D., Alpaslan, H. İ. ve Güneş, M. A. (2019). Konkordato komiserinin geçici ve kesin mühlet içerisindeki görevleri. İstanbul Sosyal Bilimler Dergisi, 24, 46-54.

Koç, F. ve Uzay, Ş. (2020). Konkordato sürecinin işletmelerin sürekliliğine katkısı. Muhasebe ve Vergi Uygulamaları Dergisi, 13 (2), $495-515$.

Konca, N. K. (2018). Konkordato uygulamalarına ilişkin beklentiler ve riskler. Analiz, 263, 1-19.

Özdemir, M. (2018). Konkordatonun muhasebe işlemlerine etkisi. Giresun Üniversitesi İktisadi ve İdari Bilimler Dergisi, 4 (8), 1-12. 
Özdemir, M. (2019). Konkordato talebinde adli muhasebe desteği. Balkan ve Yakın Doğu Sosyal Bilimler Dergisi, 5 (2), $16-22$.

Serçemeli, M. ve Okutan, A. (2019). Konkordato projesine muhasebe açısından bakış: bir vaka analizi. Business\&Management Studies: An International Journal, 7 (4), 1510-1529.

Sürmen, Y. (2020). Muhasebe 2. Trabzon: Celepler Matbaacilık.

Temiz, H. (2019). Konkordato sürecinde muhasebeleştirme işlemleri. Avrasya Sosyal ve Ekonomi Araştırmaları Dergisi, 6 (5), 268 -278.

TÜRMOB. (2019, Şubat 16). Konkordato sürecine giren borçludan olan alacakların hangi durumlarda şüpheli alacak sayılacağı. Er işim adresi https://www.turmob.org.tr/ekutuphane/detailPdf/af582adc-5994-4e89-8d19-493ca450c70c/_

Uyar, T. (2019). Yeni konkordato hukukumuzun temel ilkeleri (2. Baskı). Ankara: Türkiye Barolar Birliği Yayınları.

Yavuz, M. (2019). Konkordato hukukunda alacaklıların itiraz ve dava hakları. Mali Çözüm, 29 (152), 211-221. 